\title{
Phenotypic Variability in Fraternal Twins with PEX1 Mutations: Zellweger Syndrome with Discordant Clinical Phenotype
}

\section{Janet Simons ${ }^{1}$ and Malgorzata JM Nowaczyk ${ }^{2,3 *}$}

${ }^{1} M D$ Program, De Groote School of Medicine, McMaster University, USA

${ }^{2}$ Department of Pediatrics, McMaster University, USA

${ }^{3}$ Department of Pathology and Molecular Medicine, McMaster University, USA

\begin{abstract}
Perioxisomal biogenesis disorders are a group of genetically and clinically variable disorders affect very-long chain fatty acid metabolism. Many PEX genes have been implicated in various disorders of the Zellweger syndrome spectrum (ZSS). Here we report the cases of fraternal twins who share the same PEX1 mutations and biochemical abnormalities classic ZSS, but who have a discordant clinical presentation. While twin A had classical clinical features of Zellweger Syndrome (ZS), twin B's neonatal presentation was much milder and she may not have been initially identified as having ZSS had it not been for her brother's presentation. The twins had nearly identical biochemical markers of peroxisome function. This report highlights the wide spectrum of ZSS and suggests that its variability cannot be accounted for by genetics, biochemistry, or even intrauterine environment.
\end{abstract}

Keywords: Zellweger syndrome; PEX1 mutations; Fraternal twins

\section{Introduction}

Zellweger syndrome (OMIM 214100) is the prototype disorder of a group of peroxisomal biogenesis disorders (PBD) with wide genotypic and phenotypic heterogeneity. No fewer than 13 separate complementation groups, representing mutations in 13 of the peroxisomal proteins, peroxins, coded by PEX genes, have been identified as causing the Zellweger phenotype [1]. All have classic autosomal recessive inheritance pattern. In classical Zellweger syndrome, death within the first year of life is common, but patients with PBD who survive this milestone are frequently observed to reach school age $[1,2]$. The reasons for this phenotypic variation are unclear. While some variation has been linked to genotype, phenotypic variation within gene mutation groups is well documented [3]. Other suggestions for the existence of a milder phenotype in some patients include that of peroxisomal mosacism, in which individuals show variable expressivity between tissues or within the same tissue.

We report here on what we believe to be the first documented case of significant intra-familial phenotypic variability, in the form of fraternal twins with Zellweger syndrome. While these children share the same PEX mutations leading to ZSS, as well as an intrauterine environment, they display highly discordant phenotypes.

\section{Clinical Reports}

These dichorionic, diamniotic twins were born at term to healthy, non-consaginous parents at 37.5 weeks gestation. Conception was by IUI following administration of fertility drugs. Mother was a 37 year old G6 T1 L0 woman with a complex history of fetal loss, including four miscarriages before week 10 , and one stillbirth at 40 weeks. The parents had normal karotypes and there was no family history of fetal loss or genetic disorders on either side.

\section{Case 1}

On ultrasound at 28 weeks gestation twin A, a male child, had signs of ventriculomegaly, clubfeet, and a suspicion of hypertelorism and micrognathia. The parents elected to forgo further investigations. Twin A was born first, via spontaneous vaginal delivery. Apgars were 6 at one minute and 7 at five minutes. Birth weight was $2.533 \mathrm{~kg}\left(25^{\text {th }}\right.$ percentile), height was $45 \mathrm{~cm}$ ( $20^{\text {th }}$ percentile), and head circumference was 33.2 $\mathrm{cm}\left(40^{\text {th }}\right.$ percentile). There was initial respiratory depression requiring
30 seconds of positive pressure ventilation. He had high-pitched cry and episodes of jerking, horizontal nystagmus, and tongue thrusting lasting approximately 30 seconds. Several 10-15 second episodes of tonic-clonic seizure activity were also observed. He had hypotonia and reduced spontaneous movements. He had hypertelorism, flattened nasal bridge, thin filtrum, and a very large anterior fontanelle (Figure 1A). Skeletal survey showed stippling of the patellae; abdominal ultrasound showed cortical cysts of the kidneys. Brain MRI showed colpocephaly, cavum septum pellucidum, cavum vergae, hypoplastic corpus callosum and gyral anomalies.

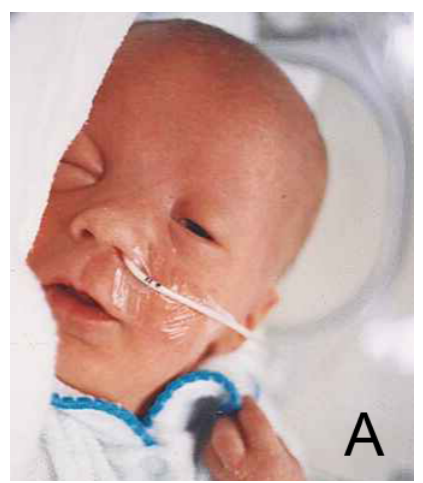

Figure 1A: Twin A as a newborn showing the severe facial dysmorphism with underdeveloped supraorbital ridge, wide nasal bridge, bilateral epicanthal folds, long philtrum, micgrognatha, facial hypotonia and low set ears.

*Corresponding author: Malgorzata JM Nowaczyk, MD, Department of Pathology and Molecular Medicine and Department of Pediatrics, McMaster University McMaster University Medical Centre, 1200 Main Street West, Room 3N16, Hamilton ON, Canada L8S 4J9; Tel: 905-521-5085; Fax: 905-521-2651; E-mail: nowaczyk@hhsc.ca

Received January 19, 2013; Accepted February 26, 2013; Published February 28, 2013

Citation: Simons J, Nowaczyk MJM (2013) Phenotypic Variability in Fraternal Twins with PEX1 Mutations: Zellweger Syndrome with Discordant Clinical Phenotype. Genetics S5: 001. doi:10.4172/2161-1041.S5-001

Copyright: (C) 2013 Simons J, et al. This is an open-access article distributed under the terms of the Creative Commons Attribution License, which permits unrestricted use, distribution, and reproduction in any medium, provided the original author and source are credited. 
The clinical diagnosis of ZS was confirmed by demonstrating elevated serum very long chain fatty acids (Table 1). Microscopic studies of fibroblasts showed sparse, enlarged peroxisomes without catalase co-localization. Elevated VLCFAS and decreased plasmalogen synthesis was also documented (Table 2).

He continued to have frequent apnea and poor handling of oral secretions. On day 12 of life he developed necrotizing enterocolitis and died on day 14 of life following worsening of his respiratory status.

\section{Case 2}

Twin B was born after her brother by emergency C-section due to breech presentation, failure to progress, and fetal bradycardia. Apgars were 6 at one minute and 8 at five minutes. Birth weight was $2.407 \mathrm{~kg}\left(20^{\text {th }}\right.$ percentile), height was $45 \mathrm{~cm}$ ( $15^{\text {th }}$ percentile), and head circumference was $32 \mathrm{~cm}$ ( $25^{\text {th }}$ percentile).

Unlike her brother, twin B did not show obvious facial dysmorphisms (Figure 1B). Axial hypotonia was noted along with lethargy after 10-15 minutes of activity. Cranial ultrasound revealed a small subependymal right hemorrhage and associated bilateral flare and no CNs structural abnormalities. Skeletal survey was normal with no evidence of epiphyseal stippling. Abdominal ultrasound was normal. Her neonatal

\begin{tabular}{|l|c|c|c|}
\hline & Twin A & Twin B & Controls (range) \\
\hline VLCFAs & & & \\
\hline C24:C22 & 2.209 & 2.620 & $0.0545-0.941$ \\
\hline C26:0 $(\mu \mathrm{mol} / \mathrm{L})$ & 7.010 & 5.880 & $0.269-0.923$ \\
\hline C26:1 $(\mu \mathrm{mol} / \mathrm{L})$ & 9.630 & 7.780 & $0.247-1.095$ \\
\hline C26:C22 & 0.701 & 0.736 & $0.005-0.017$ \\
\hline Phytanic acid $(\mu \mathrm{mol} / \mathrm{L})$ & 1.2 & 1.2 & $<10$ \\
\hline
\end{tabular}

Table 1: Serum Levels of very long chain Fatty acids (VLCFA) and phytanic acid in both twins, on day one of life.

\begin{tabular}{|c|c|c|c|}
\hline & Twin A & Twin B & Controls (range) \\
\hline VLCFAs & & & \\
\hline $\mathrm{C} 22(\mu \mathrm{g} / \mathrm{mg}$ protein) & 0.610 & 0.691 & $0.50-1.30$ \\
\hline $\mathrm{C} 26: 0(\mu \mathrm{g} / \mathrm{mg}$ protein) & 0.353 & 0.402 & $0.03-0.11$ \\
\hline $\mathrm{C} 26: 1(\mu \mathrm{g} / \mathrm{mg}$ protein) & 0.450 & 0.488 & $0.02-0.16$ \\
\hline $\mathrm{C} 26 / \mathrm{C} 22$ & 0.579 & 0.581 & $0.05-0.11$ \\
\hline Plasmalogen Synthesis & & & \\
\hline${ }^{14} \mathrm{C} /{ }^{3} \mathrm{H}$ & 0.234 & 0.204 & $0.99-2.31$ \\
\hline${ }^{3} \mathrm{H} /{ }^{14} \mathrm{C}$ & 4.415 & 4.939 & $0.48-0.86$ \\
\hline
\end{tabular}

Serum levels of very long chain fatty acids.

Table 2: Very long chain fatty acid (VLCFA) concentrations and levels of plasmalogen synthesis in cultured fibroblasts.

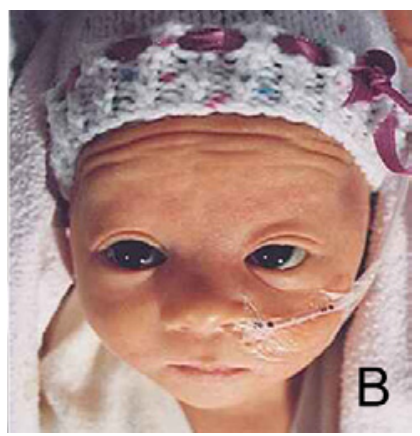

Figure 1B: Twin B as a newborn with relatively normal facial appearance with minimal bilateral epicanthal folds.

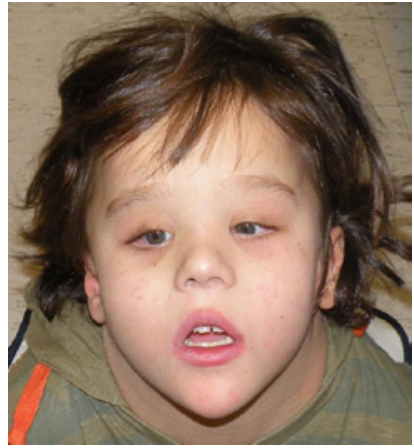

Figure 2: Twin B, age 10, with a myopathic face, underdeveloped supraorbital ridge bilateral epicanthal folds, wide nasal bridge, and pointed chin. Skin rash is secondary to liver dysfunction.

course included a mild case of hyperbilirubinemia which resolved quickly with phototherapy. She gained weight well until day 7 , when, like her brother, she developed necrotizing enterocolitis. However, she recovered and was discharged with G-tube feeds. Elevated plasma VLCFAs were demonstrated (Tables 1 and 2) and a diagnosis of ZS was made.

From the age six years her course was significant for upper GI bleeding secondary to esophageal varices, portal vein thrombosis, multiple duodenal erosions and hepatic dysfunction. She has also had recurrent UTIs and pneumonia, but has recovered well each time. At 10 years of age, she continues to do well. There are ongoing issues of developmental and motor delay. She is non-mobile, is deaf, non-verbal, hyperactive, and has episodes of self-abuse.

Sequencing of the PEX1 gene (OMIM 602136) performed at the age of eight years in the surviving twin B showed two previously reported mutations: Nt2528G $>$ A (Gly843Asp) and Nt 1109insA (frame shift mutation with a premature stop codon in exon 5). Both have been reported in patients with ZSS $[4,5]$. The parents declined carrier testing.

\section{Discussion}

These fraternal twins presented at birth with clinical and biochemical features compatible with a disorder of peroxisome biogenesis. While biochemical markers were similar, the clinical presentations of the twins were discordant. In twin A abnormalities were observed prenatally, at birth he was severely hypotonic, and had many other features of ZS including epiphyseal stippling, cortical cysts of the kidneys, and severe brain malformations. Twin B, had minimal facial dysmorphisms, minimal hypotonia, no epiphyseal stippling, and no internal malformations; her presentation and subsequent course was more in keeping with the milder end of the peroxisome biogenesis disorders such as infantile refsum disease [1]. While we do not have the genetic data on Twin A we assume that he had the same genotype as his sister.

The varying presentation in these twins cannot be attributed to differences in peroxisomal function, as biochemical testing of VLCFAs and plasmalogen synthesis (Tables 1 and 2) revealed no significant differences between them. The PEX1-G843D mutation is a temperature sensitive mild mutation and is more susceptible to variability. There is more variability in general between patients who are compound heterozygotes for a severe mutation with G843D versus those who have two severe or two mild mutations: this variability, possibly influenced by other genetic and non-genetic factors, may be responsible for the discrepancy in the clinical presentation of these siblings. 
We note also that though the twins shared an intrauterine environment, they do not share a gender and indeed it may be the gender difference that underlies the discordant presentation; however, gender differences in ZS have not been reported to date. This example of intra-familial variation suggests that some factors determining the severity of the clinical course of diseases on the Zellweger spectrum remain unidentified. Since the discovery of the genes involved in Zellweger spectum disorders we have come to appreciate the wide spectrum of these conditions. What is surprising in these cases is the discrepancy in the severity within the same family and with the same combination of mutations. In the case of Twin B, her presentation was much less severe and less indicative of a peroxisomal disorder (i.e., no epiphyseal stippling, no renal or hepatic cysts, no CNS malformations), to the point that the diagnosis of a peroxisomal disorder might not have been considered had it not been for classic presentation of Zellweger syndrome in her brother.

These cases demonstrate that while there have been many genotypephenotype correlations drawn for various genotypic groups in ZSS, some of the variation cannot be attributed to genetic variation. Nor can biochemical markers act as reliable predictors of the severity of the presentation or prognosis for the patient. These are important facts for making decisions surrounding the management of these children.

\section{References}

1. Steinberg SJ, Raymond GV, Braverman NE, Moser AB (2012) Peroxisome Biogenesis Disorders, Zellweger Syndrome Spectrum.

2. Poll-The BT, Gootjes J, Duran M, De Klerk JB, Wenniger-Prick LJ, et al (2004) Peroxisome biogenesis disorders with prolonged survival: phenotypic expression in a cohort of 31 patients. Am J Med Genet A 126A: 333-338.

3. Moser HW (1999) Genotype-phenotype correlations in disorders of peroxisome biogenesis. Mol Genet Metab 68: 316-327.

4. Steinberg S, Chen L, Wei L, Moser A, Moser H, et al. (2004) The PEX Gene Screen: molecular diagnosis of peroxisome biogenesis disorders in the Zellweger syndrome spectrum. Mol Genet Metab 83: 252-263.

5. Maxwell MA, Allen T, Solly PB, Svingen T, Paton BC, et al. (2002) Novel PEX1 mutations and genotype-phenotype correlations in Australasian peroxisome biogenesis disorder patients. Hum Mutat 20: 342-351. 